\title{
Influences of Physicochemical Stresses on Injury and Inactivation Behaviour of Listeria Innocua
}

\author{
Fátima A. Miller ${ }^{a}$, BÁrbara Ramos ${ }^{a}$, Maria M. Gil ${ }^{b}$, Teresa R. S. Brandẽo ${ }^{a}$, \\ Paula Teixeira a , and Cristina L. M. Silva ${ }^{a^{*}}$ \\ a Centro de Biotecnologia e Química Fina (CBQF), Laboratório Associado, Escola Superior de Biotecnologia, \\ Universidade Católica Portuguesa/Porto,Rua Arquiteto Lobão Vital, Apartado 2511, Porto 4202-401, Portugal \\ b ESTM, Marine Resources Research Group, Polytechnic Inst. of Leiria, Peniche, Portugal \\ ${ }^{*}$ Corresponding author \\ clsilva@porto.ucp.pt \\ TEL: +351225580058
}

Received: 1 July 2016; Published online: 18 October 2017

\begin{abstract}
Many minimally processed foods depend on a combination of inhibitory factors to reduce the hazard of foodborne illness. Therefore, inactivation of Listeria innocua was studied according to a $2^{4}$ factorial experiment designed to draw conclusions about temperature $\left(52.5{ }^{\circ} \mathrm{C}\right.$ and $\left.65.0{ }^{\circ} \mathrm{C}\right), \mathrm{pH}(4.5$ and 7.5$)$, water activity $\left(\mathrm{a}_{w}=0.95\right.$ and 0.99$)$ and solute type $(\mathrm{NaCl}$ and glycerol) effects. Three different recovery media were used to assess injured cells. Survival data were fitted with a Gompertz-based model and kinetic parameters (shoulder, maximum inactivation rate $-\mathrm{k}_{\max }$, and tail) were estimated. Results showed that shoulder was affected by temperature, $\mathrm{pH}$ and combined effects; $\mathrm{k}_{\max }$ was influenced by all factors and their combinations; and tail was affected by $\mathrm{a}_{w}$, temperature and $\mathrm{a}_{w} / \mathrm{pH}$ combination. Results demonstrated the potential occurrence of microbial cross-protection survival techniques between the various stresses, e.g. heat and osmolarity. Indeed, this work clearly established that, to avoid hazards, Listeria inactivation must be evaluated with a maximum of environmental factors that undergo alterations. Only thus, appropriate food preservation treatments can be developed and consequently, the safety of food products can be assured.
\end{abstract}

Keywords: Listeria; Microbial thermal inactivation; $\mathrm{pH} ; \mathrm{a}_{w}$; Injury

\section{Introduction}

Pathogenic bacteria in food may encounter different stressing conditions such as high or low temperature, $\mathrm{pH}$ and water activity $\left(\mathrm{a}_{w}\right)$ values. Listeria monocytogenes, the cause of listeriosis, is widespread in the environment and has been found in raw and ready-to-eat vegetables, meat, poultry, seafood and dairy products (Mena et al., 2004; Wang et al., 2013). L. monocytogenes can grow at refrigerated temperatures, has the ability to tolerate acidic conditions and can survive on dry surfaces (Norrung, 2000). Consequently, control of this bacterium is a major challenge for the food producers, since it can adapt to food environments, which normally restrict bacterial growth.

A non-pathogenic species of Listeria is Listeria innocua. This bacterium is often used as a thermal processing surrogate for $L$. monocytogenes (Kondjoyan \& Portanguen, 2008; Char, Guerrero, \& Alzamora, 2009), since they share similar characteristics and environments. Besides the criticism of some researchers in assuming the parallelism of both species in a variety of foods and processing conditions, there are a considerable 
number of works that validate $L$. innocua as a primary non-pathogenic indicator of L. monocytogenes (Zhang, Ma, Oyarzabal, \& Doyle, 2007; Lecompte, Kondjoyan, Sarter, Portanguen, \& Collignan, 2008). The similarity of growth properties of both species in a wide range of temperatures, $\mathrm{pH}$ and water activity values re-enforces the choice of working with a non-pathogenic species (Begot, Lebert, \& Lebert, 1997). The majority of $L$. innocua strains are more heat resistant than L. monocytogenes, thus providing a margin of safety in the development/design of new thermal processes involving these microorganisms (Friedly et al., 2008).

The extreme resistance of Listeria spp. to many food preservation conditions leads to the application of hurdle combinations that allow milder processing conditions, but still effective in bacteria control (Barker \& Park, 2001). In foods, microorganisms are exposed to multiple physicochemical stresses that may, individually or simultaneously, affect their behaviour. However, due to the importance of heat processing in the food industry, researcher's attention has been given to temperature effects. Until recently, few studies had given importance to the combination of other stressful factors, such as $\mathrm{pH}$ and $\mathrm{a}_{w}$, and their effect on microbial stress-adaptation and crossprotection.

Although it has been widely assumed that combined hurdles have additive or synergistic mode of action, some studies (Casey \& Condon, 2002; Lee \& Kang, 2009) reported antagonistic effects. Therefore, it is crucial to study the effects of several relevant stress factors on microbial inactivation to avoid extended survival problems.

Some of the main important hurdles used in food preservation are temperature, $\mathrm{pH}$ and $\mathrm{a}_{w}$. When a thermal process is applied, the heat resistance of microorganisms is influenced by the physicochemical conditions during heating. Among them, $\mathrm{a}_{w}$ is one of the most important. Data available in literature revealed that when $\mathrm{a}_{w}$ decreases, a marked increase in microbial thermal resistance is often observed. Results also suggested that the heat resistance of bacteria depends both on strain and type of solute chosen (Mazas, Martinez, Lopez, Alvarez, \& Martin, 1999; Coroller, Leguerinel, \& Mafart, 2001). The $\mathrm{pH}$ of the heating media is also an important factor that influences the thermal microbial inactivation. As $\mathrm{pH}$ decreases, the microbial heat resistance decreases, so less severe heat treatments may be used to achieve safe products (Miller, Ramos, et al., 2009).

Exposure to a combination of these stressing factors may also induce sublethal physiological and structural changes in cells. These are called injured cells and may have the potential to recover when favourable conditions occur. The majority of techniques for enumerating $L$. monocytogenes requires culturing with selective media. If media do not support the growth of injured cells, the quantitative detection of viable cells can be compromised (Bremer, Osborne, Kemp, \& Smith, 1998).

According to the treatment conditions used, the microbial inactivation behaviour may not follow a linear tendency (McKellar \& Lu, 2003; Huang, 2009) and initial lags and/or final tailing tendencies may precede and/or follow the maximum inactivation rate period (i.e. sigmoidal kinetics). Therefore, there are several mathematical models that describe non-linear behaviour (Geeraerd, Herremans, \& Van Impe, 2000; Albert \& Mafart, 2005; Gil, Brandao, \& Silva, 2006).

Thus, the objectives of this study were: (i) to evaluate the influence of temperature, $\mathrm{pH}, \mathrm{a}_{w}$ and type of solute ( $\mathrm{NaCl}$ or glycerol) on the inactivation behaviour of L. innocua, and (ii) to determine the incidence of injured cells after each treatment using three platting media.

\section{Materials and Methods}

\subsection{The experimental design}

A $2^{4}$ factorial design (Box, Hunter, \& Hunter, 1978) was applied to assess the effect of (i) temperature, (ii) $\mathrm{pH}$, (iii) water activity and (iv) type of solute used to vary $\mathrm{a}_{w}$, on the log reduction of $L$. innocua evaluated by shoulder, $\mathrm{k}_{\max }$ and tail parameters of the Gompertz-based model (equation 1, section 2.3.). The levels assumed for the variables were: (i) 52.5 and $65.0{ }^{\circ} \mathrm{C}$ for temperature, (ii) 4.5 and 7.5 for $\mathrm{pH}$, (iii) 0.95 and 0.99 for water activity and (iv) $\mathrm{NaCl}$ and glycerol for the type of solute used (totalling 16 cases). Three replicates of all the combinations 
were performed.

\subsection{Experimental procedures}

\section{Cultures}

Listeria innocua NCTC 10528 was subcultured $\left(30^{\circ} \mathrm{C}, 24 \mathrm{~h}\right)$ in Tryptic Soy Broth - TSB (Lab M, Lancashire, UK) containing $0.6 \%$ yeast extract TSBYE (Lab M). Cultures were maintained at 7 ${ }^{\circ} \mathrm{C}$ on Tryptic Soy Agar - TSA (Lab M) supplemented with $0.6 \%$ yeast extract - TSAYE.

\section{Preparation of cultures}

The second subculture of L. innocua was incubated at $30{ }^{\circ} \mathrm{C}$ for $20 \mathrm{~h}$ to yield stationary phase cultures. This cell growth phase was chosen due to its higher stress resistance than exponential phase cells (Miller, Gil, Brandao, Teixeira, \& Silva, 2009). Cells in each cellular suspension were enumerated by plating appropriate dilutions, in duplicate, on the three solid media studied. The initial Listeria concentration was then calculated for each cellular suspension.

\section{Log reduction experiments in broth}

TSBYE was used as the basal medium for all experiments. Combinations of temperature (52.5 and $\left.65.0{ }^{\circ} \mathrm{C}\right), \mathrm{pH}(4.5$ and 7.5$), \mathrm{a}_{w}$ (0.95 and $0.99)$ and type of solute $(\mathrm{NaCl}$ and glycerol Merck) were studied according to the experimental design. The $\mathrm{pH}$ was always adjusted with lactic acid $(0.5 \mathrm{M})$ and measured using a $\mathrm{pH}$ meter (GLP 22, Crison Instruments, Spain). Water activity determinations were performed with a dew point hygrometer (Aqualab - Series 3, Decagon Devices Inc., USA) at $25 \pm 1^{\circ} \mathrm{C}$.

The $\mathrm{pH}$ and $\mathrm{a}_{w}$ of the media were measured before and after autoclaving. Autoclaving did not change medium $\mathrm{pH}$ or $\mathrm{a}_{w}$.

Heat treatments were carried out in a thermostatized water bath. A covered Erlenmeyer flask containing ninety-nine milliliters of stirred TSBYE, adjusted to the specified $\mathrm{pH}$ and $\mathrm{a}_{w}$, was immersed in the water bath. Once the heating medium temperature had attained stability (measured with a thermometer), it was inoculated with $1 \mathrm{~mL}$ of cell suspension. Samples were removed from the stirred TSBYE at different time intervals and immediately placed in a mixture of ice-water.

Samples were serially diluted and plated in duplicate onto three different media: (i) TSAYE, (ii) TSAYE supplemented with $5 \%(\mathrm{w} / \mathrm{v})$ sodium chloride - TSAYE + NaCl and (iii) Palcam Agar plus selective supplement (Miller, Brandao, Teixeira, \& Silva, 2006). Plates were incubated at 30 ${ }^{\circ} \mathrm{C}$ and counted each $24 \mathrm{~h}$ during 5 days, or until the number of colony formation units (cfu) no longer increased.

Mean values of bacterial counts, from duplicate plate samples, were converted to log numbers for each combination.

\subsection{Modelling Procedures}

\section{The inactivation model}

Assuming that the microbial thermal inactivation follows a sigmoidal behaviour, experimental data can be mathematically described by a Gompertz-based model (Linton, Carter, Pierson, \& Hackney, 1995; Gil et al., 2006):

$$
\log \left(\frac{N}{N_{0}}\right)=\log \left(\frac{N_{\text {res }}}{N_{0}}\right) e^{-e^{\frac{-k_{\text {max }} e}{\log \frac{N_{\text {res }}}{N_{0}}}(L-t)+1}}
$$

where $\mathrm{N}$ is the microbial cell density at a particular process time, t. The indexes 0 and res indicate initial and residual (or tail) microbial cell density, respectively, $\mathrm{L}$ is the initial shoulder and $\mathrm{k}_{\max }$ the maximum inactivation rate.

The versatility of fitting linear data and those that contain shoulder and/or tailing effects makes Gompertz an attractive model (Gil, Miller, Brandao, \& Silva, 2011).

\section{Data analysis}

The parameters of the Gompertz inactivation model, i.e. $\mathrm{L}, \mathrm{k}_{\max }$ and $\log \left(\mathrm{N}_{\text {res }} / \mathrm{N}_{0}\right)$, were estimated by non-linear regression analysis, fitting equation 1 to experimental data.

The quality of the regressions was evaluated by the coefficient of determination $\left(\mathrm{R}^{2}\right)$, randomness and normality of the residuals.

Parameters' precision was evaluated by the standardised half width (SHW) at $95 \%$, i.e. halved 
confidence interval divided by the estimate $=$ (confidence interval $\left.{ }_{95 \%} / 2\right) \times\left(1 /\right.$ estimate) x 100 . $^{2}$ Results from the $2^{4}$ factorial experimental design were analysed by ANOVA procedures.

The heat resistance of microorganisms has been traditionally expressed in terms of D-values (decimal reduction time, or time required to inactivate $90 \%$ of the population). These values are calculated assuming that microbial inactivation follows first order kinetics and can be calculated using data of the maximum inactivation rate period, where the $\mathrm{D}$-value is the reciprocal of $\mathrm{k}_{\max }$.

$$
D=\frac{1}{k_{\max }}
$$

Statistica ${ }^{\circledR} 6.0$ (StatSoft, USA) and Microsoft ${ }^{\circledR}$ Excel 2000 (Microsoft Corporation, USA) were used for all calculations and statistical analysis.

\section{Results and Discussion}

\subsection{Thermal inactivation behaviour of L. innocua}

This study aimed at determining the influence and interactions of temperature, $\mathrm{pH}, \mathrm{a}_{w}$ and type of solute (used to change $\mathrm{a}_{w}$ ) on the inactivation of $L$. innocua 10528. Although some works have proven the significant influence of temperature, $\mathrm{pH}$ and $\mathrm{a}_{w}$ on microbial inactivation (Blackburn, Curtis, Humpheson, Billon, \& McClure, 1997; Juneja \& Eblen, 1999; Jagannath, Nakamura, \& Tsuchido, 2003), studies of their effects on the features of non-linear inactivation kinetics (this meaning initial shoulders, maximum inactivation rate and tail) are scarce. Therefore, the effect of these factors on kinetic parameters was now studied using the conditions defined according to the $2^{4}$ experimental design. The Gompertzbased model was fitted to experimental inactivation data, and kinetic parameters were estimated for all situations considered. These results are included in Tables 1 and 2, respectively for $\mathrm{a}_{w}=0.95$ and 0.99 . The kinetic behaviour of L. innocua for all conditions tested can be visualized in Fig. 1. The initial concentration of $L$. innocua was determined to be approximately $10^{7}$ cfu $\mathrm{mL}^{-1}$ for all conditions tested. The adequacy of model fits was assessed by residual analysis (i.e. residuals were random, and normally distributed with mean equal to zero and constant variance). Values of the coefficient of determination, $\mathrm{R}^{2}$, were in all cases above 0.92 , revealing model adequacy in data description.

In relation to the precision of the kinetic parameters, shoulder was estimated with the lowest precision (assessed by the standardized half width at $95 \%$ ). The experimental design used may explain this lack of precision, since less experimental points were gathered in the initial inactivation period. This was evident in the cases where higher temperatures and lower $\mathrm{pH}$ were imposed (the shoulder does not occur).

Results of the experimental design analysis showed that, with the exception of the type of solute, all factors significantly affected the maximum inactivation rate (at a significance level of 5\%). Although the major effect was due to temperature, the following main effects and combinations had also a significant influence on $\mathrm{k}_{\text {max }}: \mathrm{pH}$, temperature $/ \mathrm{pH}, \mathrm{a}_{w}, \mathrm{a}_{w} / \mathrm{pH}$, $\mathrm{a}_{w} /$ temperature, $\mathrm{a}_{w} / \mathrm{pH} /$ temperature.

For shoulder parameter, the temperature, $\mathrm{pH}$ and the combination temperature/pH were the factors that significantly affected this kinetic parameter (at a significance level of $13 \%$ ). The occurrence of a shoulder can be attributed to differences in cell's resistance. While some treated cells may be totally injured, avoiding their culturability/survival, others might have sublethal damage that makes them more sensitive to the subsequent treatment exposure. In cases where L. innocua was treated at high temperature and subjected to lactic acid, the shoulder became almost inexistent, which means the instantly unviability of the majority of Listeria cells. The combination of these two factors was very effective in microbial inactivation, which is indicative of their synergistic effect. This behaviour has also been observed in other studies (Juneja \& Eblen, 1999; Lee \& Kang, 2009). Although it has been reported that organic acids' effectiveness increases with temperature increase, this fact can be affected by other factors such as the type of acidifier and microorganism.

In relation to tail parameter, $\mathrm{a}_{w}$ was the most significant factor, followed by temperature and the combined effect of $\mathrm{a}_{w} / \mathrm{pH}$ (at a significance level of $30 \%$ ). The tail suggests an apparently 
increased resistance of $L$. innocua in the later stages of the treatment exposure. As pointed out by several researchers (Booth, 1998; Rowan, 1999), these survivors are likely to be physiologically protected from the stress exposure. In this case, the lower the $\mathrm{a}_{w}$, the higher the thermoresistance of Listeria cells.

Temperature had a positive effect on $\mathrm{k}_{\max }$ and tail parameter, which means higher inactivation rates are observed and the tail tendency becomes evident when temperature rises. Concerning the shoulder, the temperature effect is negative. The shoulder period becomes less visible for higher temperatures. These effects revealed that, although temperature is very lethal in microbial reduction, some thermoresistance is obtained in the later stages of the heat treatment.

The $\mathrm{pH}$ affected $\mathrm{k}_{\max }$ and shoulder, but not the tail parameter. Lowering $\mathrm{pH}$ value implies higher inactivation rates and narrow shoulders, which indicates that acidic $\mathrm{pH}$ is very effective on Listeria inactivation. Water activity positively influenced $\mathrm{k}_{\max }$ and tail, which means lower inactivation rates are observed and the tail tends to disappear when $\mathrm{a}_{w}$ decreases. In this case, some microbial stress adaptative response is occurring, which increases the time of the bacterium survival. However, once energy consumption is required to activate microbial repair mechanisms, L. innocua cells may become metabolically exhausted and die sometime after.

By observing the results shown in Table 1 and Fig. 1, it is possible to conclude that shoulder times were higher when glycerol was used (instead of $\mathrm{NaCl}$ ) and for lower temperatures, higher $\mathrm{pH}$ values and rich media (i.e. TSAYE). For lower temperatures, lower $\mathrm{pH}$ values and when glycerol was used, higher shoulders and lower inactivation rates were observed. Consequently, the overall heat resistance was higher when compared to $\mathrm{NaCl}$ results. The influence of glycerol on the initial shoulder can be explained by the immediate intracellular access of glycerol as a result of direct passage through the cell membrane. The non-permeability of the cell membrane to $\mathrm{NaCl}$ may lead to the differences observed when both solutes are used.

\subsection{Physicochemical stresses}

As already said, and when dealing with an analysis of variance, the temperature (followed by $\mathrm{pH}$ and $\mathrm{a}_{w}$ ) had the major significant impact in the inactivation behaviour. These great effects made the influence of the solute type negligible. However, if the temperature and $\mathrm{pH}$ effects were not considered, L. innocua inactivation may be influenced by the solute used to change $\mathrm{a}_{w}$. This can be better understood with the results presented in Fig. 2, where D-values are represented for $\mathrm{a}_{w}$ of 0.95 (with $\mathrm{NaCl}$ and glycerol used as solutes) and $\mathrm{a}_{w}$ of 0.99 (without solute addition). For $\mathrm{pH}$ media of 7.5, L. innocua was more heat resistant when $\mathrm{NaCl}$ was used to change $\mathrm{a}_{w}$. This was observed for the lower and higher temperatures tested. However, for media $\mathrm{pH}$ of 4.5 and for the lower temperature, an inverted tendency was observed. In this case, L. innocua became more heat resistant if glycerol had been used. Several studies demonstrated that the water activity effect depends on the treatment temperature. Coroller et al. (2001) and Chiewchan, Pakdee, and Devahastin (2007) concluded that $\mathrm{a}_{w}$ effect was more pronounced at higher heating temperatures. Mattick et al. (2001), when studying the heat tolerance of Salmonella spp., demonstrated that for temperatures equal or higher than $70{ }^{\circ} \mathrm{C}$ the bacterial cells were more heat tolerant at low $\mathrm{a}_{w}$ than those at higher $\mathrm{a}_{w}$. At temperatures below $65{ }^{\circ} \mathrm{C}$ the reverse was observed, which is in agreement with our results. The hightemperature target(s) appears to be protected by low $\mathrm{a}_{w}$, perhaps through improved stability of proteins, reduced mobility of water, or the direct effects of solutes, whereas the lower-temperature target(s) is clearly not protected by low $\mathrm{a}_{w}$. In this work, the combination of high temperature with low $\mathrm{a}_{w}$, also increased the survival of $L$. innocua (antagonistic effect) in the majority of the situations tested. However, this was not the case for conditions (i) $\mathrm{T}=52.5{ }^{\circ} \mathrm{C}$ and $\mathrm{pH}=4.5$ using $\mathrm{NaCl}$ and (ii) $\mathrm{T}=65.0{ }^{\circ} \mathrm{C}$ and $\mathrm{pH}=7.5$ using glycerol, where $L$. innocua cells were more susceptible to heat (Fig. 1). These different results are probably due to the combination of several stressful conditions. A synergistic effect can be achieved when different stresses reach different targets within the microbial cells (e.g., cell 
$144 \mid$ Miller et al.
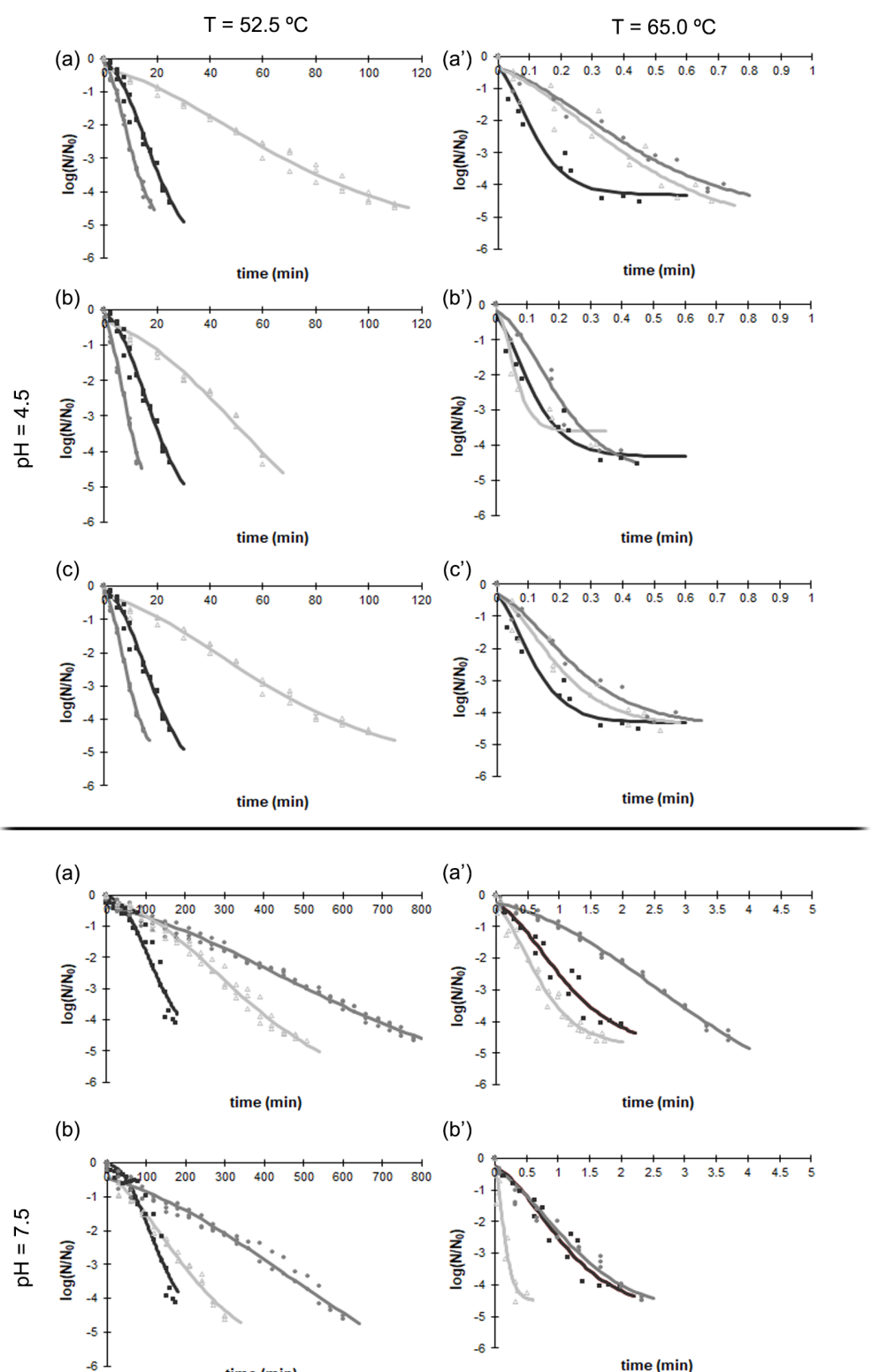

(b')
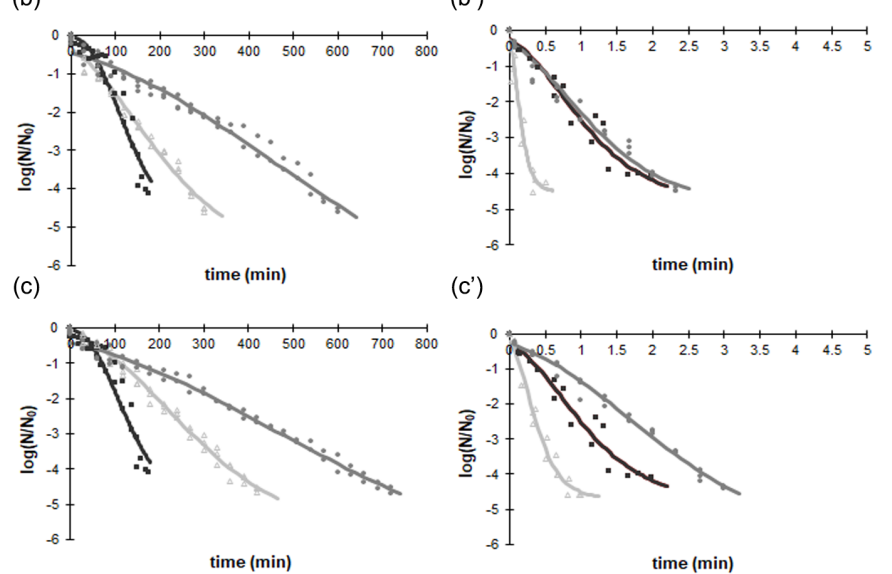

(c')

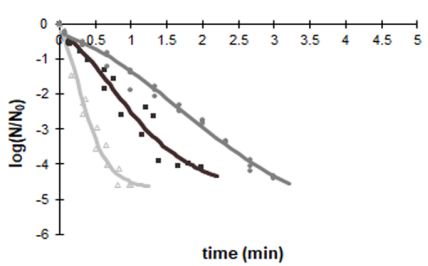

Figure 1: Thermal inactivation data of L. innocua at all conditions of $\mathrm{pH}$ and temperature, using the three recovery media: (a) and (a') TSAYE; (b) and (b') TSAYE + 5\% NaCl; (c) and (c') Palcam Agar. Each plot has a survival curve for $\mathrm{a}_{w}$ of $0.99(\boldsymbol{\square})$ and 0.95 , this last one adjusted with $\mathrm{NaCl}(\bullet)$ or glycerol $(\triangle)$. The lines represent model fits (Eq. 1). 
L. innocua inactivation kinetics $\mid 145$

Table 1: Estimated shoulder, maximum inactivation rate and tail parameters of L. innocua 10528 at $\mathrm{a}_{w}$ 0.95, for all conditions tested.

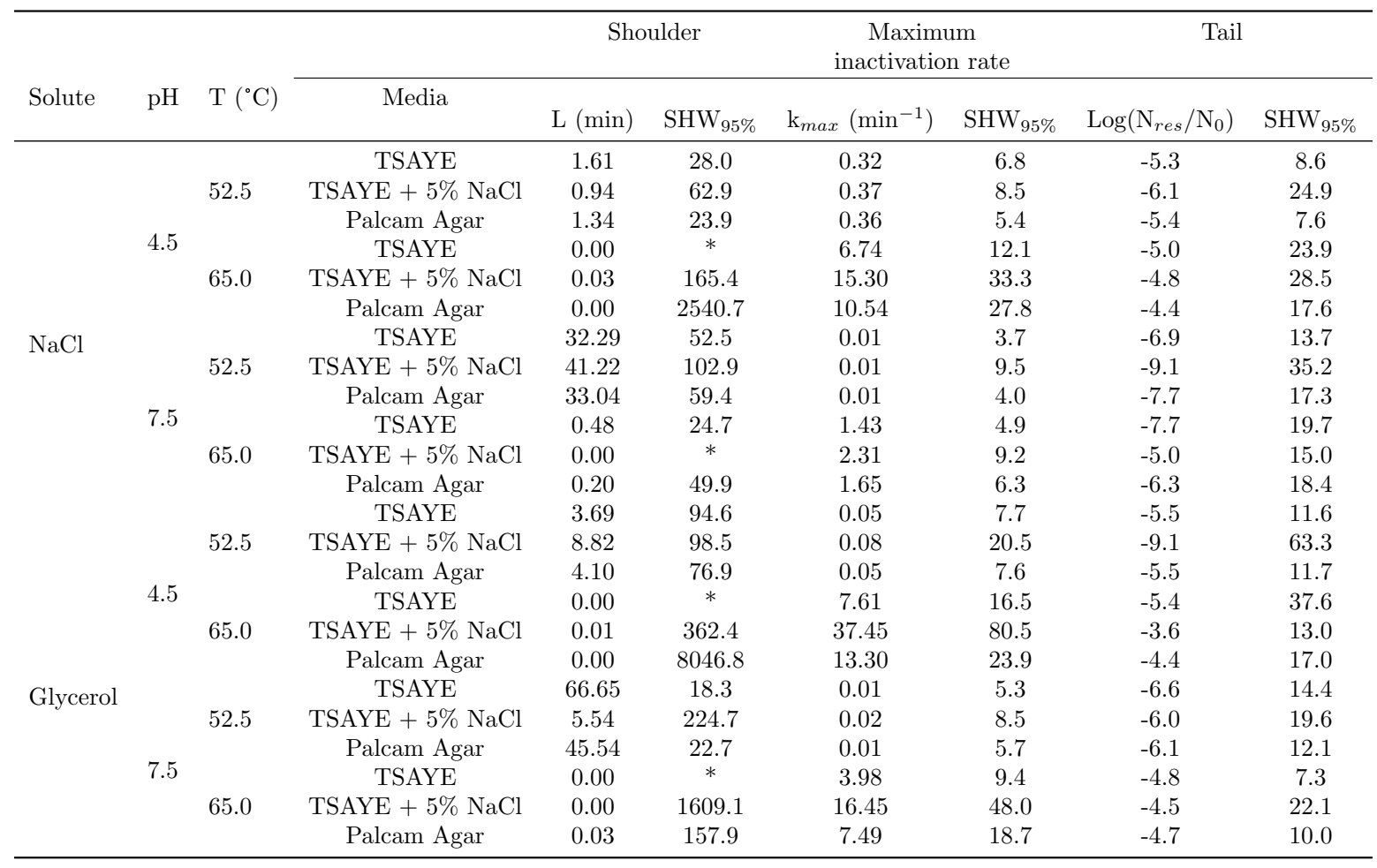

TSAYE: Tryptic Soy Agar supplemented with $0.6 \%$ yeast extract.

* Considerable high meaningless value.

Table 2: Estimated shoulder, maximum inactivation rate and tail parameters of L. innocua 10528 at aw 0.99 , for all conditions tested.

\begin{tabular}{|c|c|c|c|c|c|c|c|c|}
\hline \multirow[t]{2}{*}{$\mathrm{pH}$} & \multirow[t]{2}{*}{$\mathrm{T}\left({ }^{\circ} \mathrm{C}\right)$} & \multirow[t]{2}{*}{ Media } & \multicolumn{2}{|c|}{ Shoulder } & \multicolumn{2}{|c|}{$\begin{array}{c}\text { Maximum } \\
\text { inactivation rate }\end{array}$} & \multicolumn{2}{|c|}{ Tail } \\
\hline & & & $\mathrm{L}(\min )$ & SHW $_{95 \%}$ & $\mathrm{k}_{\max }\left(\min ^{-1}\right)$ & $\mathrm{SHW}_{95 \%}$ & $\log \left(\mathrm{N}_{\text {res }} / \mathrm{N}_{0}\right)$ & SHW $95 \%$ \\
\hline \multirow{7}{*}{4.5} & \multirow{3}{*}{52.5} & TSAYE & 4.23 & 20.9 & 0.22 & 7.2 & -6.2 & 21.2 \\
\hline & & TSAYE + $5 \% \mathrm{NaCl}$ & 1.57 & 38.1 & 0.37 & 10.9 & -5.1 & 12.9 \\
\hline & & Palcam Agar & 3.16 & 29.6 & 0.25 & 10.2 & -5.8 & 22.9 \\
\hline & \multirow{4}{*}{65.0} & TSAYE & 0.00 & 9877.6 & 21.19 & 29.4 & -4.3 & 13.4 \\
\hline & & TSAYE + $5 \% \mathrm{NaCl}$ & 0.00 & 4490.3 & 500.93 & 4424.4 & -4.5 & 9.3 \\
\hline & & Palcam Agar & 0.00 & 2087.9 & 50.25 & 45.4 & -4.2 & 12.5 \\
\hline & & TSAYE & 40.00 & 32.9 & 0.03 & 16.4 & -5.2 & 48.3 \\
\hline \multirow{5}{*}{7.5} & \multirow[t]{2}{*}{52.5} & TSAYE + $5 \% \mathrm{NaCl}$ & 0.00 & * & 0.09 & 39.9 & -3.4 & 21.9 \\
\hline & & Palcam Agar & 20.00 & 111.1 & 0.04 & 35.5 & -8.2 & 79.9 \\
\hline & \multirow{3}{*}{65.0} & TSAYE & 0.06 & 338.8 & 2.68 & 26.6 & -4.8 & 30.1 \\
\hline & & $\mathrm{TSAYE}+5 \% \mathrm{NaCl}$ & 0.02 & 100.0 & 29.64 & 34.2 & -3.9 & 15.8 \\
\hline & & Palcam Agar & 0.01 & 868.2 & 8.88 & 38.7 & -4.0 & 18.8 \\
\hline
\end{tabular}

TSAYE: Tryptic Soy Agar supplemented with $0.6 \%$ yeast extract.

* Considerable high meaningless value.

IJFS | October 2017 | Volume 6 | pages 139-151 
membrane, DNA, enzyme systems). This situation will require extensive energy-consumption to maintain internal homeostasis which may cause the microorganisms to become metabolically exhausted (Leistner, 2000). Stress reactions due to a particular stress factor might also lead to the microorganism becoming more tolerant to other stressful conditions. This phenomenon is called "cross-tolerance" (Leistner, 2000).

Studies on the combined effects of organic acids and solutes on pathogens survival are scarce. Casey and Condon (2002) showed that NaCl reduced the inhibitory effect of lactic acid on $E$. coli by raising its cytoplasmic $\mathrm{pH}\left(\mathrm{pH}_{i}\right)$. In contrast with these findings, Fang, Siegumfeldt, Budde, and Jakobsen (2004) and Lebert, Dussap, and Lebert (2004) observed a significant decrease in $\mathrm{pH}_{i}$ following exposure to high concentrations of $\mathrm{NaCl}$. However, when glycerol was added to the medium to decrease $\mathrm{a}_{w}$, they observed that $\mathrm{pH}_{i}$ remained constant. As recognized, weak acids in their unprotonated form can diffuse into the cell and dissociate, thereby lowering the intracellular $\mathrm{pH}$. In the presence of glycerol, the free $\mathrm{H}^{+}$resulted from the acid dissociation will be buffered, which consequently promotes the stability of $\mathrm{pH}_{i}$. In the presence of $\mathrm{NaCl}$, the concentration of free $\mathrm{H}^{+}$will rise, due to the lack of buffering capacity of the salt, and therefore the $\mathrm{pH}_{i}$ decreases.

This fact, together with the capacity of glycerol to diffuse freely across the inner membrane, can explain our results at $\mathrm{pH} 4.5$, where the glycerol had less inhibitory effect than $\mathrm{NaCl}$ at $52.5{ }^{\circ} \mathrm{C}$. At $65.0{ }^{\circ} \mathrm{C}$, the temperature and $\mathrm{a}_{w}$ effects are more notable as is the similarity of the results for the two solutes.

At neutral $\mathrm{pH}$, opposite results were observed. When $\mathrm{NaCl}$ was used as the solute, L. innocua was more heat resistant. Mazas et al. (1999) and Stewart et al. (2002) arrived at similar conclusions. Listeria spp. is recognized to tolerate high concentrations of $\mathrm{NaCl}$ and this adaptability appears to be related to the capacity of the bacteria to accumulate intracellular solutes. The work of Patchett, Kelly, and Kroll (1992) showed that L. monocytogenes accumulates $\mathrm{K}^{+}$, betaine and glutamate to provide compensation for the osmotic stress caused by increased salinity. These findings suggested that not only osmotic stress but also physicochemical properties of the solutes used to control $\mathrm{a}_{w}$, as well as the biological effects of the solutes on the microorganism, lead to variation of cell behaviour. In fact, the protective influence of $\mathrm{a}_{w}$ decrease could be balanced by a specific antagonistic and toxic effect of glycerol, at neutral $\mathrm{pH}$.

\subsection{Effect of plating media}

The heat resistance of microorganisms is frequently evaluated in terms of D-value. Such an approach assumes linearity between the logarithmic of the number of viable microorganisms with time (this meaning a linear kinetics). Deviations from linearity can be observed in the results presented in Fig. 1, for the majority of the conditions tested. For all studied conditions, $\mathrm{k}_{\max }$ values were converted to D-values (Eq. 2). D-values calculated using data obtained in nonselective media (TSAYE) and in selective media (TSAYE $+5 \% \mathrm{NaCl}$ and Palcam Agar) are shown in Fig. 2.

In all cases, D-values using TSAYE were the highest as this medium supports the growth of most cells, including those that can suffer any kind of injury. D-values for selective media are likely to be lower as the growth of injured cells is prevented. In the case of TSAYE $+\mathrm{NaCl}$, a lower survival of Listeria means that the osmoregulatory functions of the cytoplasmic membrane has been damaged. Those cells, where some enzymes may be inactivated by the replacement of their cations by $\mathrm{Li}^{+}$, will be sensitive to $\mathrm{LiCl}$ in Palcam Agar. For the conditions of Fig. 2a and 2c (lower temperature), it is possible to note that $\mathrm{D}$ values obtained using TSAYE $+\mathrm{NaCl}$ were lower than those determined using TSAYE for $\mathrm{a}_{w}$ of 0.99, but the ones from Palcam Agar are similar to those obtained in non-selective medium. This indicates that under high $\mathrm{a}_{w}$ heating conditions, a great number of bacteria survivors had cytoplasmic membrane damage and that for high and low $\mathrm{a}_{w}$ cell injury in enzymes functionality is not relevant. For the situation presented in Fig. 2d (higher temperature and higher $\mathrm{pH}$ ), D-values determined using both selective media were lower than those obtained using TSAYE for $\mathrm{a}_{w}$ of 0.99 and when glycerol was utilized 
(a)

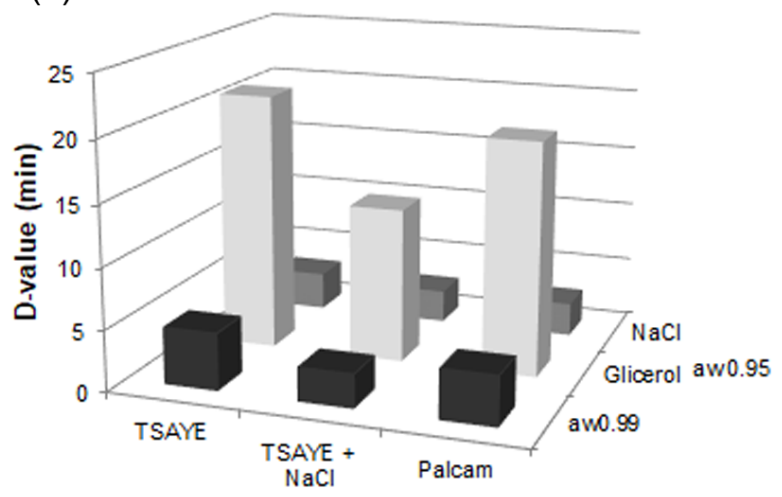

(c)

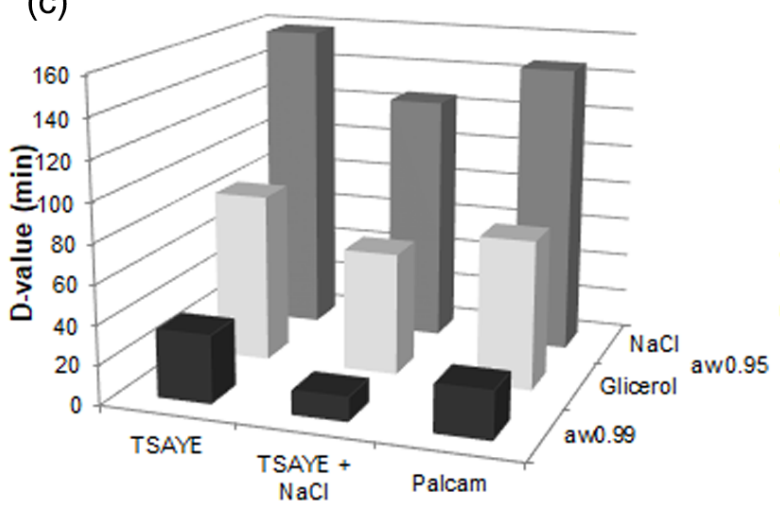

(b)

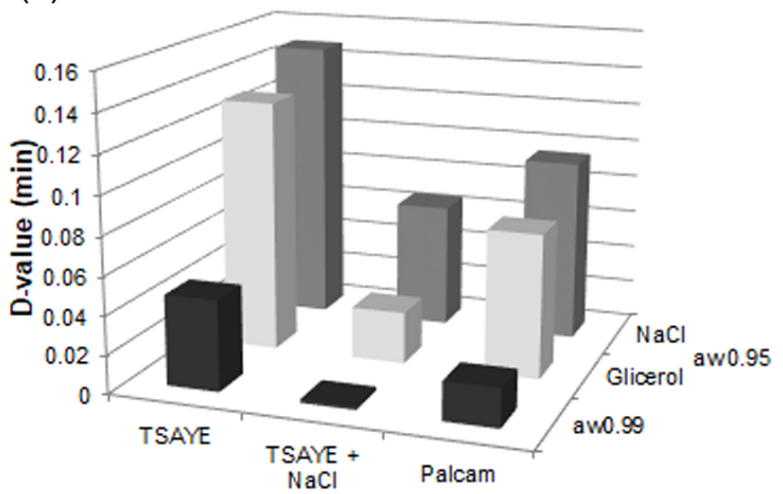

(d)

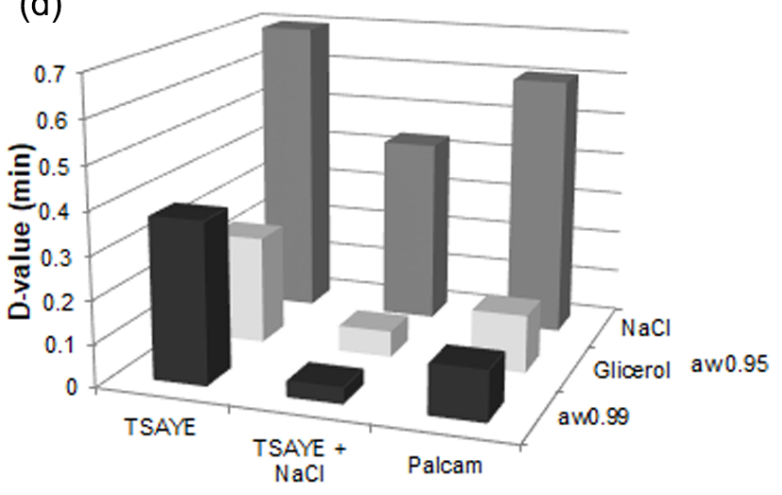

Figure 2: D-values of L. innocua treated at (a) $\mathrm{pH}=4.5$ and $\mathrm{T}=52.5^{\circ} \mathrm{C}$, (b) $\mathrm{pH}=4.5$ and $\mathrm{T}=65.0^{\circ} \mathrm{C},(\mathrm{c})$ $\mathrm{pH}=7.5$ and $\mathrm{T}=52.5{ }^{\circ} \mathrm{C}$ and $(\mathrm{d}) \mathrm{pH}=7.5$ and $\mathrm{T}=65.0^{\circ} \mathrm{C}$, at $\mathrm{a}_{w}$ of 0.99 and 0.95 , this last one adjusted with $\mathrm{NaCl}$ or glycerol, for three different recovery media.

to decrease $\mathrm{a}_{w}$ to 0.95 . This implies that under these conditions many survivors may have cytoplasmic membrane damage and enzymes inactivation. For the most severe conditions tested (Fig. 2b; higher temperature and lower $\mathrm{pH}$ ) no distinct differences were observed for D-values calculated for the three media used. This is indicative that survivors did not suffer any form of injury that can be repaired. All these conclusions were validated by the D-values calculated (lacking associated uncertainty), and the $\mathrm{k}_{\max }$ estimates and related precision. This allowed significance of the highlighted conclusions. From these results it is possible to conclude that lower tem- peratures potentiate the inactivation of Listeria cells with damaged cytoplasmic membranes. It is also important to note that at $52.5^{\circ} \mathrm{C}$ and at high $\mathrm{a}_{w}$, cells with damaged cytoplasmic membranes survive and can repair. However, when they are heated in a medium with low $\mathrm{a}_{w}$, the additional osmotic stress caused by any solute may result in cell death rather than sublethal injury. As referred by Gabriel (2013) aside from some protection conferred by solutes against heat injury, the decrease in $\mathrm{a}_{w}$ also brings forth physical damage to cellular membranes and provides reduction of intracellular moisture which can negatively affect the function of cellular enzymes. Exposures to

\begin{tabular}{l|l|l|l} 
IJFS & October 2017 & Volume 6 & pages 139-151
\end{tabular} 
acidic environments are also known to induce disruption of biochemical processes within the cells such as enzymes functions and nutrient transport (Beales, 2004). At higher temperatures, the study of Aljarallah and Adams (2007) showed that ribosomal inactivation was a primary target of cell damage.

\section{Conclusions}

To achieve accurate results concerning the thermal inactivation of microorganisms, it is crucial to study the influence of relevant factors. Although the results from the present work pointed out that temperature was the main significant factor that influences $L$. innocua survival, $\mathrm{pH}$ and $\mathrm{a}_{w}$ (and their combined effects) had also a significant impact. If temperature and $\mathrm{pH}$ effects were not considered, L. innocua inactivation may also be affected by the solute used to change $\mathrm{a}_{w}$. For media $\mathrm{pH}$ of 7.5, L. innocua is more heat resistant when $\mathrm{NaCl}$ is used to change $\mathrm{a}_{w}$. This is observed for the lower and higher temperatures tested. However, for media $\mathrm{pH}$ of 4.5 and for the lower temperature, an inverted tendency was observed. In this case, L. innocua became more heat resistant if glycerol is used. These results suggest that some physicochemical properties of the solutes used to control $\mathrm{a}_{w}$ may influence the microbial thermal resistance. A further comparison of results, where the $\mathrm{a}_{w}$ effect is considered alone, may lead to restricted conclusions.

Care must be taken with the enumeration media chosen, since selective media may be inadequate for the recovery of injured Listeria cells. Comparing results obtained in selective media with the ones obtained in non-selective media, it can be concluded that at lower temperature, Listeria inactivation occurred by damage in the cytoplasmic membrane, which can be repaired at high $\mathrm{a}_{w}$ (0.99), but not at low $\mathrm{a}_{w}(0.95)$.

Every attempt should be made to control relevant important processing conditions that affect microbial survival. Special attention must be given to the possible interactions between these factors, as synergistic or antagonistic effects may happen.

\section{Acknowledgements}

Fátima A. Miller and Teresa R.S. Brandão gratefully acknowledge, respectively, their PostDoctoral Grants (SFRH/BPD/65041/2009) and (SFRH/BPD/101179/2014) to Fundação para a Ciência e a Tecnologia (FCT). This work was supported by National Funds from FCT Fundação para a Ciência e a Tecnologia through project UID/Multi/50016/2013.

\section{References}

Albert, I. \& Mafart, P. (2005). A modified weibull model for bacterial inactivation. International Journal of Food Microbiology, 100(1-3), 197-211. 4th International Conference on Predictive Modelling in Foods, Quimper, FRANCE, JUN 15-19, 2003. doi:10.1016/j.ijfoodmicro.2004.10.016

Aljarallah, K. M. \& Adams, M. R. (2007). Mechanisms of heat inactivation in salmonella serotype typhimurium as affected by low water activity at different temperatures. Journal of Applied Microbiology, 102(1), 153-160. doi:10.1111/j.1365-2672. 2006. 03054.x

Barker, C. \& Park, S. F. (2001). Sensitization of listeria monocytogenes to low ph, organic acids, and osmotic stress by ethanol. Applied and Environmental Microbiology, 67(4), 1594-1600. doi:10.1128/AEM.67. 4.1594-1600.2001

Beales, N. (2004). Adaptation of microorganisms to cold temperatures, weak acid preservatives, low ph, and osmotic stress: a review. Comprehensive Reviews in Food Science and Food Safety, 3(1), 1-20. doi:10. 1111/j.1541-4337.2004.tb00057.x

Begot, C., Lebert, I., \& Lebert, A. (1997). Variability of the response of 66 listeria monocytogenes and listeria innocua strains to different growth conditions. Food Microbiology, 14(5), 403-412. doi:10.1006/fmic . 1997.0097

Blackburn, C. D., Curtis, L. M., Humpheson, L., Billon, C., \& McClure, P. J. (1997). Development of thermal inactivation models for salmonella enteritidis and escherichia coli 
o157 : h7 with temperature, ph and nacl as controlling factors. International Journal of Food Microbiology, 38(1), 31-44. doi:10. 1016/S0168-1605(97)00085-8

Booth, I. R. (1998). The bacteria strike back. The Biochemist, 20, 8-11.

Box, G. E. P., Hunter, W. G., \& Hunter, J. S. (1978). Statistics for experiments: an introduction to design, data analysis and model building. New York: John Wiley \& Sons. Retrieved from https:// hwbdocuments. env.nm.gov / Los \% 5C \% 20Alamos \% 5C \% 20National\%5C\%20Labs/TA\%5C\%2054/ 11528.pdf

Bremer, P. J., Osborne, C. M., Kemp, R. A., \& Smith, J. J. (1998). Survival of listeria monocytogenes in sea water and effect of exposure on thermal resistance. Journal of Applied Microbiology, 85(3), 545-553. doi:10.1046/j.1365-2672.1998.853533.x

Casey, P. G. \& Condon, S. (2002). Sodium chloride decreases the bacteriocidal effect of acid ph on escherichia coli o157 : h45. International Journal of Food Microbiology, 76 (3), 199-206. doi:10.1016/S01681605(02)00018-1

Char, C., Guerrero, S., \& Alzamora, S. M. (2009). Survival of listeria innocua in thermally processed orange juice as affected by vanillin addition. Food Control, 20(1), 6774. doi:10.1016/j.foodcont.2008.02.004

Chiewchan, N., Pakdee, W., \& Devahastin, S. (2007). Effect of water activity on thermal resistance of salmonella krefeld in liquid medium and on rawhide surface. International Journal of Food Microbiology, 114(1), 43-49. doi:10.1016/j.ijfoodmicro. 2006.10.037

Coroller, L., Leguerinel, I., \& Mafart, P. (2001). Effect of water activities of heating and recovery media on apparent heat resistance of bacillus cereus spores. Applied and Environmental Microbiology, 67(1), 317-322. doi:10.1128/AEM.67.1.317-322.2001

Fang, W. H., Siegumfeldt, H., Budde, B. B., \& Jakobsen, M. (2004). Osmotic stress leads to decreased intracellular ph of listeria monocytogenes as determined by fluorescence ratio-imaging microscopy. Applied and Environmental Microbiology, 70(5),
3176-3179. doi:10.1128/AEM.70.5.31763179.2004

Friedly, E. C., Crandall, P. G., Ricke, S., O'Bryan, C. A., Martin, E. M., \& Boyd, L. M. (2008). Identification of listeria innocua surrogates for listeria monocytogenes in hamburger patties. Journal of Food Science, 73(4), M174-M178. doi:10. 1111/j.I750-3841.2008.00719.x

Gabriel, A. A. (2013). Influences of simultaneous physicochemical stresses on injury and subsequent heat and acid resistances of salmonella enteritidis in apple juice. Food Control, 31(1), 28-34. doi:10.1016/ j . foodcont.2012.08.021

Geeraerd, A. H., Herremans, C. H., \& Van Impe, J. F. (2000). Structural model requirements to describe microbial inactivation during a mild heat treatment. International Journal of Food Microbiology, 59(3), 185209. doi:10.1016/S0168-1605(00)00362-7

Gil, M. M., Brandao, T. R. S., \& Silva, C. L. M. (2006). A modified gompertz model to predict microbial inactivation under timevarying temperature conditions. Journal of Food Engineering, 76(1), 89-94. doi:10 . 1016/j.jfoodeng.2005.05.017

Gil, M. M., Miller, F. A., Brandao, T. R. S., \& Silva, C. L. M. (2011). On the use of the gompertz model to predict microbial thermal inactivation under isothermal and non-isothermal conditions. Food Engineering Reviews, 3(1), 17-25. doi:10.1007/ s12393-010-9032-2

Huang, L. (2009). Thermal inactivation of listeria monocytogenes in ground beef under isothermal and dynamic temperature conditions. Journal of Food Engineering, 90(3), 380-387. doi:10.1111/j.1471-0307. 2008.07.011

Jagannath, A., Nakamura, I., \& Tsuchido, T. (2003). Modelling the combined effects of ph, temperature and sodium chloride stresses on the thermal inactivation of bacillus subtilis spores in a buffer system. Journal of Applied Microbiology, 95(1), 135-141. 18th International ICFMH Symposium, LILLEHAMMER, NORWAY, AUG 18-23, 2002. doi:10.1046/j.1365-2672. 2003.01952.x 
Juneja, V. K. \& Eblen, B. S. (1999). Predictive thermal inactivation model for listeria monocytogenes with temperature, ph, nacl, and sodium pyrophosphate as controlling factors. Journal of Food Protection, 62(9), 986-993.

Kondjoyan, A. \& Portanguen, S. (2008). Effect of superheated steam on the inactivation of listeria innocua surface-inoculated onto chicken skin. Journal of Food Engineering, 87(2), 162-171. doi:10.1016/j . jfoodeng . 2007.11.030

Lebert, I., Dussap, C. G., \& Lebert, A. (2004). Effect of $\mathrm{a}(\mathrm{w})$, controlled by the addition of solutes or by water content, on the growth of listeria innocua in broth and in a gelatine model. International Journal of Food Microbiology, 94(1), 67-78. doi:10.1016/j. ijfoodmicro.2004.01.002

Lecompte, J.-Y., Kondjoyan, A., Sarter, S., Portanguen, S., \& Collignan, A. (2008). Effects of steam and lactic acid treatments on inactivation of listeria innocua surfaceinoculated on chicken skins. International Journal of Food Microbiology, 127(1-2), 155-161. doi:10.1016/j.ijfoodmicro. 2008. 06.033

Lee, S.-Y. \& Kang, D.-H. (2009). Combined effects of heat, acetic acid, and salt for inactivating escherichia coli o157:h7 in laboratory media. Food Control, 20(11), 10061012. doi:10.1016/j.foodcont.2008.12.002

Leistner, L. (2000). Basic aspects of food preservation by hurdle technology. International Journal of Food Microbiology, 55(13), 181-186. International Symposium on Microbial Stress and Recovery in Food, QUIMPER, FRANCE, JUN 14-16, 1999. doi:10.1016/S0168-1605(00)00161-6

Linton, R. H., Carter, W. H., Pierson, M. D., \& Hackney, C. R. (1995). Use of a modified gompertz equation to model nonlinear survival curves for listeria-monocytogenes scott-a. Journal of Food Protection, 58(9), 946-954.

Mattick, K. L., Jorgensen, F., Wang, P., Pound, J., Vandeven, M. H., Ward, L. R., ... Humphrey, T. J. (2001). Effect of challenge temperature and solute type on heat tolerance of salmonella serovars at low water activity. Applied and Environmental Microbiology, 67(9), 4128-4136. doi:10.1128/ AEM.67.9.4128-4136.2001

Mazas, M., Martinez, S., Lopez, M., Alvarez, A. B., \& Martin, R. (1999). Thermal inactivation of bacillus cereus spores affected by the solutes used to control water activity of the heating medium. International Journal of Food Microbiology, 53(1), 6167. doi:10.1016/S0168-1605(99)00145-2

McKellar, R. C. \& Lu, X. (2003). Modeling microbial responses in food. CRC Press. doi:10.1201/9780203503942

Mena, C., Almeida, G., Carneiro, L., Teixeira, P., Hogg, T., \& Gibbs, P. A. (2004). Incidence of listeria monocytogenes in different food products commercialized in portugal. Food Microbiology, 21 (2), 213-216. doi:10.1016/ S0740-0020(03)00057-1

Miller, F. A., Brandao, T. R. S., Teixeira, P., \& Silva, C. L. M. (2006). Recovery of heat-injured listeria innocua. International Journal of Food Microbiology, 112(3), 261265. 19th International ICFMH Symposium on Food Micro, Potoroz, SLOVENIA, 2004. doi:10.1016/j.ijfoodmicro. 2006.04. 013

Miller, F. A., Gil, M. M., Brandao, T. R. S., Teixeira, P., \& Silva, C. L. M. (2009). Sigmoidal thermal inactivation kinetics of listeria innocua in broth: influence of strain and growth phase. Food Control, 20(12), 1151-1157. doi:10.1016/j . foodcont . 2009. 03.007

Miller, F. A., Ramos, B., Gil, M. M., Brandao, T. R. S., Teixeira, P., \& Silva, C. L. M. (2009). Influence of ph, type of acid and recovery media on the thermal inactivation of listeria innocua. International Journal of Food Microbiology, 133(1-2), 121-128. doi:10.1016/j.ijfoodmicro.2009.05.007

Norrung, B. (2000). Microbiological criteria for listeria monocytogenes in foods under special consideration of risk assessment approaches. International Journal of Food Microbiology, 62(3, SI), 217-221. doi:10 . 1016/S0168-1605(00)00338-X

Patchett, R. A., Kelly, A. F., \& Kroll, R. G. (1992). Effect of sodium-chloride on the intracellular solute pools of listeria- 
L. innocua inactivation kinetics $\mid 151$

monocytogenes. Applied and Environmental Microbiology, 58(12), 3959-3963.

Rowan, N. J. (1999). Evidence that inimical food-preservation barriers alter microbial resistance, cell morphology and virulence. Trends in Food Science 83 Technology, 10(8), 261-270. doi:10.1016/S09242244(99)00060-6

Stewart, C. M., Cole, M. B., Legan, J. D., Slade, L., Vandeven, M. H., \& Schaffner, D. W. (2002). Staphylococcus aureus growth boundaries: moving towards mechanistic predictive models based on solutespecific effects. Applied and Environmental Microbiology, 68(4), 1864-1871. doi:10. 1128/AEM.68.4.1864-1871.2002

Wang, X.-M., Lu, X.-F., Yin, L., Liu, H.-F., Zhang, W.-J., Si, W., . . L Liu, S.-G. (2013). Occurrence and antimicrobial susceptibility of listeria monocytogenes isolates from retail raw foods. Food Control, 32(1), 153158. doi:10.1016/j.foodcont.2012.11.032

Zhang, G., Ma, L., Oyarzabal, O. A., \& Doyle, M. P. (2007). Aerosol studies with listeria innocua and listeria monocytogenes. Journal of Food Protection, 70 (8), 1857-1865. 